\title{
Effect of miR-140-5p on the regulation of proliferation and apoptosis in NSCLC and its underlying mechanism
}

\author{
WENWEN ZHOU ${ }^{1}$, XIAOYU WANG ${ }^{2}$, DUANDUAN YIN ${ }^{1}$, LEI XUE ${ }^{1}$, ZHONGFENG MA ${ }^{1}$, ZHENZHEN WANG ${ }^{1}$, \\ QIANYI ZHANG ${ }^{3}$, ZISHU ZHAO $^{2}$, HAIXIA WANG $^{4}$, YAN SUN $^{1}$ and YANHONG YANG ${ }^{1}$ \\ ${ }^{1}$ Department of Oncology, Qinhuangdao First People's Hospital, Qinhuangdao, Hebei 066000; \\ ${ }^{2}$ Foundation and Clinic of Malignant Tumor, Postgraduate College, Chengde Medical University, \\ Chengde, Hebei 067000, P.R. China; ${ }^{3}$ Division of Pharmacy, University of Tasmania, Hobart, \\ Tasmania 7005, Australia; ${ }^{4}$ Foundation and Clinic of Malignant Tumor, Postgraduate College, \\ Hebei Medical University, Shijiazhuang, Hebei 051117, P.R. China
}

Received May 10, 2018; Accepted January 11, 2019

DOI: $10.3892 /$ etm.2019.7701

\begin{abstract}
Non-small cell lung cancer (NSCLC) is the most common type of lung cancer accounting for $\sim 80 \%$ of lung cancer cases. According to novel research, numerous microRNAs (miRs) have been suggested to function as important regulators of cancer. In addition, the expression of miR-140-5p is decreased in patients with NSCLC. Therefore, it is important to further elucidate the role of miR-140-5p in NSCLC. Reverse transcription-quantitative polymerase chain reaction (RT-qPCR) was used in order to investigate the expression of miR-140-5p in NSCLC tissues and matched normal tissues and to determine miR-140-5p levels following transfection with mimics into A549 lung cancer cells. Targetscan software was used to predict the oncogene target of miR-140-5p. This analysis revealed that YES proto-oncogene 1 (YES1) includes a target site for miR-140-5p binding. The results revealed that YES1 is a potential target gene of miR-140-5p, and this was further confirmed by the results of luciferase reporter assays, which demonstrated that miR-140-5p directly targeted the predicted binding site in the 3'-untranslated region of YES1. Cell Counting Kit-8 (CCK-8) and flow cytometry assays were performed to determine the levels of cell viability and apoptosis. Western blot assays was performed to investigate the expression levels of YES1 and proteins associated with apoptosis in A549 cells following transfection. The results revealed that miR-140-5p expression was significantly downregulated in NSCLC tissues compared with matched normal tissues. The expression of miR-140-5p was significantly increased following transfection with miR-140-5p mimics. The results of
\end{abstract}

Correspondence to: Dr Yanhong Yang, Department of Oncology, Qinhuangdao First People's Hospital, 258 Wenhua Road, Qinhuangdao, Hebei 066000, P.R. China

E-mail: dr_yanhongyang@sina.com

Key words: microRNA-140-5p, non-small cell lung cancer, YES proto-oncogene 1 , apoptosis
CCK-8 and flow cytometry assays indicated that miR-140-5p inhibited proliferation and induced apoptosis of tumor cells. Western blot analysis and RT-qPCR revealed that YES1 and B-cell lymphoma 2 (Bcl-2) mRNA and protein expression levels were markedly decreased in A549 cells, while Bcl-2 associated X (Bax) and caspase-3 expression levels increased significantly following transfection with miR-140-5p mimics compared with the negative control group. In conclusion, miR-140-5p may induce apoptosis in A549 cells by targeting YES1 and regulating the expression of apoptosis-associated proteins Bcl-2, Bax and caspase-3.

\section{Introduction}

Lung cancer is the leading cause of cancer-associated mortality, with $\sim 1.35$ million novel cases being diagnosed each year worldwide (1). A total of $\sim 75-80 \%$ of lung cancer cases are non-small cell lung cancer (NSCLC), with the overall 5 -year survival rate of $10 \%$ (2). Despite the development of novel methods for the early diagnosis of patients as well as recent advancements in treatment strategies, the prognosis and survival rate of patients with NSCLC remain relatively poor (3). Between 40-50\% of patients with NSCLC eventually succumb to relapse or metastatic disease following curative resection (4). However, a number of prognostic biomarkers are available in clinical practice at present, particularly regarding patients who have previously undergone curative surgical resection (5). Therefore, it is important to identify novel prognostic biomarkers that may aid prognosis prediction and optimize the treatment of patients with NSCLC.

Micro (mi)RNAs (miRs) are a class of small (19-24 nucleotides in length), highly conserved non-coding RNAs that may bind to the 3'-untranslated regions (3'-UTRs) of target mRNAs and subsequently suppress the translation of such RNAs to proteins (6). It has become increasingly evident that different miRNAs may either exhibit oncogenic or tumor-suppressive roles in numerous pathways, depending on their target genes or cellular context (7-9). miRNAs are not only involved in the regulation of malignant tumor cell proliferation, but also serve an important role in tumor invasion and metastasis (10-12). 
Therefore, the role of miRNAs in NSCLC has been receiving increasing attention (13-15). miRNAs associated with different types of cancer include oncogenic miRNAs, tumor suppressive miRNAs and miRNA regulators (16). Previous studies have indicated that miRNA-140-5p serves an important role in numerous tumor types (17-20); however, studies investigated the association between miR-140-5p expression and clinical outcomes in patients with resected NSCLC are limited and have demonstrated contradictory results $(21,22)$. Therefore, the specific role of miR-140-5p in NSCLC remains to be determined.

The aim of the present study was to identify the target genes of miR-140-5p and to elucidate the regulatory mechanism underlying the association between miR-140-5p and NSCLC.

\section{Materials and methods}

Patients and tissue samples. The clinical information related to 45 NSCLC cancer cases was collected from July 2016 to 2017 at the Qinhuangdao First People's Hospital (Qinhuangdao, China). A total of 45 patients were recruited in the current study [age, 31-75 years; mean age, $53 \pm 21.8$ years; gender distribution (male: female), 26:19). All patients were diagnosed with stage III or II NSCLC. Tumor and para-carcinoma tissue samples were removed and immediately placed in liquid nitrogen or $10 \%$ formalin for in subsequent experimentation. All samples were confirmed by pathological examination, and no radiotherapy or chemotherapy was performed prior to surgery. The present study was approved by the Ethics Committee of Qinhuangdao First People's Hospital (approval no. QDPH160503) and written informed consent was obtained from each participant prior to the study.

Cell culture. A549 lung cancer cells (Shanghai Institute of Biochemistry and Cell Biology, Shanghai, China) were cultured in Roswell Park Memorial Institute (RPMI) 1640 medium (Gibco; Thermo Fisher Scientific, Inc., Waltham, MA, USA) supplemented with $10 \%$ fetal bovine serum (FBS; HyClone; GE Healthcare Life Sciences, Logan, UT, USA) and $1 \%$ penicillin/streptomycin in a $5 \% \mathrm{CO}_{2}$-humidified incubator at $37^{\circ} \mathrm{C}$.

miRNA transfection. Cells were seeded into six-well plates, incubated for $24 \mathrm{~h}$ and divided into the following three groups: Control group, untreated cells; negative control (NC) group, cells treated with $20 \mathrm{pmol} / \mu 1 \mathrm{miR}-\mathrm{NC}$ mimics; and miR-140-5p mimics (mimics) group, cells treated with $1.5 \mu \mathrm{l}$ miR-140-5p mimics. The following miRNA sequences were obtained from New England BioLabs, Inc. (Ipswich, MA, USA): miR-mimics, 5'-ACCAUAGGGUAAAACCACUGU U-3' and miR-NC, 5'-UUCUCCGAACGUGUCACGUTT-3'. Cells were transfected with $500 \mathrm{ng}$ miRNA using $2.5 \mu \mathrm{l}$ Lipofectamine ${ }^{\circledR} 2000$ (Invitrogen; Thermo Fisher Scientific, Inc.). After incubation for $6 \mathrm{~h}$, the medium was replaced with RPMI 1640 medium supplemented with 10\% FBS. After $24 \mathrm{~h}$ incubation, cells were collected and used in subsequent experimentation. The experiment was performed in triplicate.

Flow cytometry assay. Following transfection, the rate of apoptosis of A549 cells was determined using the
Annexin V-fluorescein isothiocyanate (FITC) Apoptosis Detection kit (BD Biosciences, San Jose, CA, USA) and flow cytometry. Briefly, the transfected cells were seeded into 24-well plates and incubated at $37^{\circ} \mathrm{C}$ with $15 \% \mathrm{CO}_{2}$ for $72 \mathrm{~h}$. Subsequently, cells were treated with propidium iodide $(10 \mu \mathrm{g} /$ ml; Sigma-Aldrich; Merck KGaA, Darmstadt, Germany) and Annexin V-FITC (50 $\mu \mathrm{g} / \mathrm{ml}$; BD Biosciences) in the dark for $15 \mathrm{~min}$ at room temperature. Apoptotic cells were subsequently examined using a flow cytometry (FACScan ${ }^{\mathrm{TM}}$; BD Biosciences) and Modfit software (version 3.2; Verity Software House, Inc., Topsham, ME, USA).

Reverse transcription-quantitative polymerase chain reaction $(R T-q P C R)$. Total RNA was extracted from cells using TRIzol $^{\circledR}$ reagent (Invitrogen; Thermo Fisher Scientific, Inc.) according to the manufacturer's protocol. Poly(A) polymerase was used to catalyse the addition of adenosine residues onto the 3'ends of RNA. Total RNA concentration was spectrophotometrically determined at a wavelength of $260 \mathrm{~nm}$. RNA was immediately reverse-transcribed into cDNA using the SuperScript Reverse Transcriptase (Invitrogen; Thermo Fisher Scientific, Inc.). qPCR was subsequently performed using the SYBR ${ }^{\circledR}$ Green Realtime PCR MasterMix (Toyobo Life Science, Osaka, Japan). The following primer sequences were used for qPCR: miR-140-5p forward, 5'-ACACTCCAG CTGGGAGGCGGGGCGCCGCGGGA-3' and reverse, 5'-CTCAACTGGTGTCGTGGA-3'; U6 forward, 5-'TGC GGGTGCTCGCTTCGGCAGC-3' and reverse, 5'-CCA GTGCAGGGTCCGAGGT-3'; YES1 forward, 5'-ATGCTA CAGTTGCCCCGAC-3' and reverse, 5'-TCCAAAAGGAGT CACCCCTGA-3'; Bax forward, 5'-CACCAGCTCTGAACA GATCATGA-3' and reverse, 5'-TCAGCCCATCTTCTTCCA GATGT-3'; Bcl-2 forward, 5'-CACCCCTGGCATCTTCTC CTT-3' and reverse, 5'-AGCGTCTTCAGAGACAGCCAG-3'; caspase-3 forward, 5'-AACTGGACTGTGGCATTGAG-3' and reverse, 5'-ACAAAGCGACTGGATGAACC-3'; GAPDH (352 bp) forward, 5'-AGTAGAGGCAGGGATGATGTTC-3' and reverse, 5'-CTTTGGTATCGTGGAAGGACTC-3'. The following thermocycling conditions were used for the qPCR: Initial denaturation at $95^{\circ} \mathrm{C}$ for $10 \mathrm{~min} ; 50$ cycles of $95^{\circ} \mathrm{C}$ for $15 \mathrm{sec}$ and $60^{\circ} \mathrm{C}$ for $60 \mathrm{sec}$. Each reaction was performed three times. The comparative cycle threshold method was used to analyze qPCR data and $2^{\Delta \Delta \mathrm{Cq}}$ values were used to reflect differences in the expression levels (23). GAPDH or $\mathrm{U}^{\wedge}$ were used as the reference genes.

Western blotting. Cells in the logarithmic growth phase were collected in a cell culture plate and total protein was extracted using a radioimmunoprecipitation assay buffer (Beyotime Institute of Biotechnology, Shanghai, China). Total protein was quantified using a bicinchoninic acid assay (Thermo Fisher Scientific, Inc.) and $20 \mu \mathrm{g}$ protein/lane was separated via SDS-PAGE on a $10 \%$ gel. The separated proteins were transferred onto polyvinylidene fluoride (PVDF) membranes and blocked overnight at $4{ }^{\circ} \mathrm{C}$ with $5 \%$ non-fat dried milk. The PVDF membranes were incubated with primary antibodies against YES proto-oncogene 1 (YES1; 1:1,000; cat. no. ab109265; Abcam, Cambridge, MA, USA); B-cell lymphoma 2 (Bcl-2; 1:1,000; cat. no. sc-7382; Santa Cruz Biotechnology, Inc., Dallas, TX, USA); Bcl-2 associated X 
(Bax; 1:1,000; sc-7480, Santa Cruz Biotechnology, Inc.); and caspase-3 (1:1,000; cat. no. 9662; Cell Signaling Technology, Inc., Danvers, MA, USA) for $1 \mathrm{~h}$ at $37^{\circ} \mathrm{C}$. GAPDH $(1: 1,000$; cat. no. 2118; Cell Signaling Technology, Inc.) was used as the loading control. The membranes were subsequently incubated with a horseradish peroxidase-conjugated secondary antibody (1:5,000; cat. no. ab6789; Abcam) at room temperature for $2 \mathrm{~h}$. Subsequently, protein bands were visualized using the ECL-Plus reagent (Santa Cruz Biotechnology, Inc.) and protein expression was quantified using Image-Pro Plus software (version 6.0; Media Cybernetics, Inc., Rockville, MD, USA).

Cell viability assay. Cell viability was examined using the Cell Counting Kit-8 (CCK-8). Transfected cells were seeded in 96-well plates and incubated for $24 \mathrm{~h}$. CCK-8 reagent was subsequently added into the culture medium and, following an additional $24-\mathrm{h}$ incubation step at $37^{\circ} \mathrm{C}$, the absorbance was measured at a wavelength of $450 \mathrm{~nm}$ using a microplate reader.

Relative luciferase activity assay. TargetScan bioinformatics software (www.targetscan.org/vert_71) was used to predict potential target genes of miR-140-5p, which identified YES1. To confirm the binding of miR-140-5p to YES1 mRNA, the 3'-UTR of YES1 mRNA was amplified by PCR and inserted into the pGL3/luciferase vector (Promega Corporation, Madison, WI, USA). Co-transfections with wt YES1 3'-UTR or mut YES1 3'-UTR plasmids and mimics or NC sequences were performed using Lipofectamine ${ }^{\circledR} 2000$. Luciferase activity was measured $48 \mathrm{~h}$ after transfection using the Dual-Luciferase ${ }^{\circledast}$ reporter assay system (Promega Corporation). Firefly luciferase activity was normalized to Renilla luciferase activity. Data are presented as the mean values for triplicate experiments.

Statistical analysis. Data are presented as the mean \pm standard deviation. All statistical analyses were performed using SPSS software (version 19.0; IBM Corp., Armonk, NY, USA). Student's t-test was performed to analyze the difference between two groups and one-way analysis of variance followed by Newman-Keuls post-hoc test was used to analyze differences among multiple groups. $\mathrm{P}<0.05$ was considered to indicate a statistically significant difference. All experiments were performed in triplicate.

\section{Results}

miR-140-5p is downregulated in NSCLC tissues. The expression levels of miR-140-5p in 45 samples of NSCLC tissues and paracancerous tissues were determined via RT-qPCR. The results revealed that the expression of miR-140-5p was decreased in NSCLC tissues compared with the corresponding paracancerous tissues (Fig. 1).

Expression of miR-140-5p following miRNA transfection. Cells were transfected with miR-140-5p or miR-NC mimics. The expression of miR-140-5p was significantly increased following transfection with miR-140-5p mimics compared with the NC group; however, there was no significant alteration between the control group and the miR-NC group (Fig. 2).

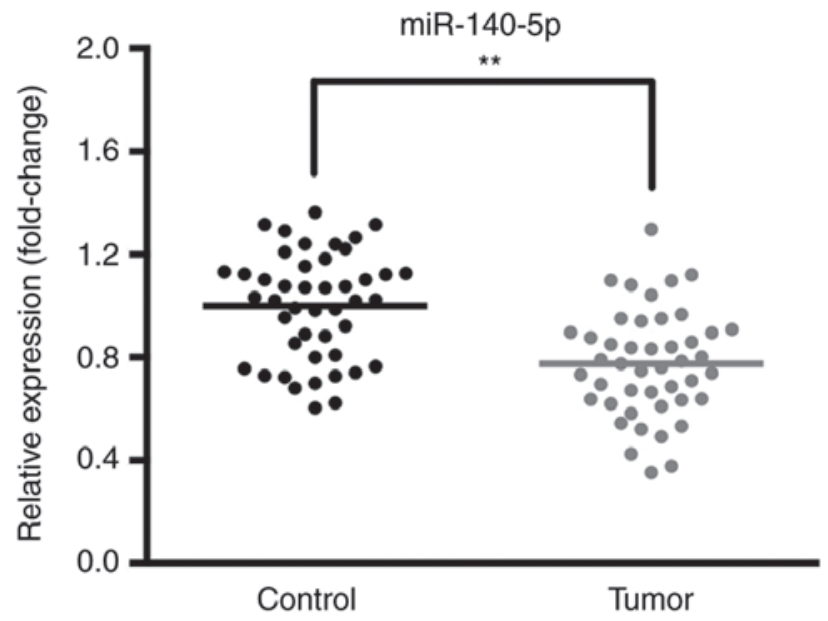

Figure 1. miR-140-5p expression is downregulated in NSCLC tissues Reverse transcription-quantitative polymerase chain reaction was performed to investigate the expression of miR-140-5p in NSCLC and paracancerous tissues. Compared with the control group, the expression of miR-140-5p in NSCLC tissues was significantly suppressed. Data are presented as the mean \pm standard deviation of three independent experiments. ${ }^{* *} \mathrm{P}<0.01$. NSCLC, non-small cell lung cancer; miR, microRNA; tumor, NSCLC tissues; control, paracancerous tissues.

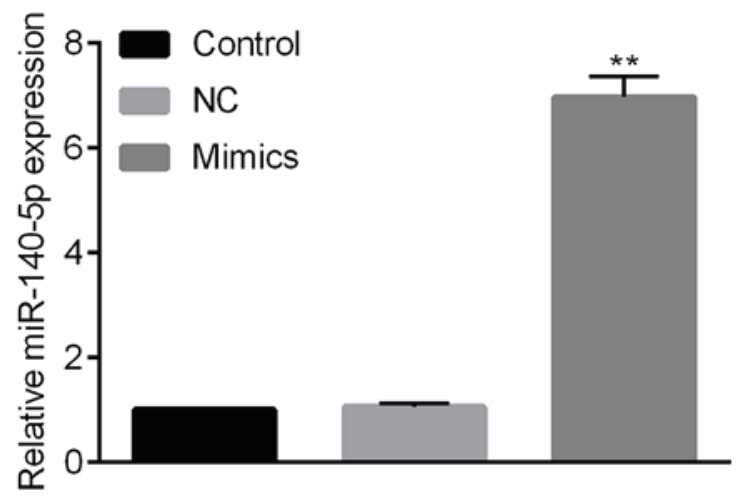

Figure 2. Expression of miR-140-5p following transfection. Following transfection with miR-140-5p mimics, the expression of miR-140-5p was significantly increased compared with the $\mathrm{NC}$ group. ${ }^{* *} \mathrm{P}<0.01$ vs. the NC group. NSCLC, non-small cell lung cancer; miR, microRNA; NC, negative control.

miR-140-5p directly targets YES1 in A549 cells. To determine the function of miR-140-5p in NSCLC, target genes of miR-140-5p were predicted using Targetscan software, and the results revealed that YES1 is a potential target gene of miR-140-5p. To investigate the potential interaction between the YES1 3'-UTR and miR-140-5p, luciferase reporter assays were performed, and the results indicated that the luciferase activity was significantly inhibited following co-transfection with pre-miR-140-5p and vectors carrying the wide type 3'-UTR of YES1 (Fig. 3).

miR-140-5p regulate the cell viability and apoptosis of NSCLC cells via targeting YES1. As demonstrated above, miR-140-5p may target YES1. Therefore, the effects of miR-140-5p on the growth of tumor cells were further investigated. CCK-8 and flow cytometry assays were performed to determine the cell viability and apoptosis of A549 cells in vitro. The 

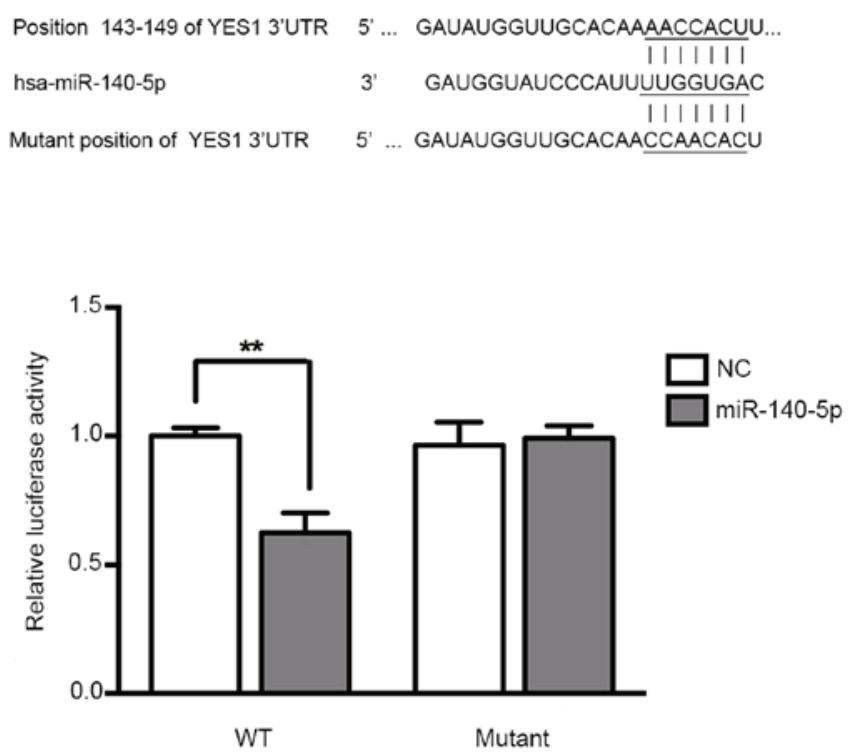

Figure 3. YES1 is a target gene of miR-140-5p. The results of Targetscan analysis suggested that YES1 may represent a target gene of miR-140-5p. Co-transfection with pre-miR-140-5p and vectors carrying WT 3'-UTR of YES1 significantly suppressed luciferase activity. Data are presented as the mean \pm standard deviation of three independent experiments. ${ }^{* *} \mathrm{P}<0.01$. YES1, YES proto-oncogene 1; miR, microRNA; 3'-UTR, 3'-untranslated region; NC, negative control; WT, wild type

rate of apoptosis of A549 cells following transfection with miR-140-5p mimics significantly increased compared with the $\mathrm{NC}$ group, and transfection with miR-140-5p mimics significantly suppressed cell viability in A549 cells compared with he NC group (Fig. 4). Therefore, miR-140-5p expression may suppress the proliferation of NSCLC cells. To further investigate whether miR-140-5p regulates the expression of YES1 and other apoptosis-associated proteins, mRNA and protein expression levels were determined. Ectopic expression of miR-140-5p in A549 cells significantly decreased the expression of YES1 and Bcl-2 compared with the NC group at the mRNA and protein level. Furthermore, the expression of Bax and caspase- 3 was significantly increased in the mimics group compared with control group (Fig. 5). The aforementioned results suggested that miR-140-5p may regulate cell viability in vitro by targeting of YES1.

\section{Discussion}

Lung cancer is the only malignant tumor for which morbidity and mortality rates have been increasing in recent years (1). In addition, lung cancer has become the leading cause of cancer-associated mortality worldwide (1). Lung cancer is pathologically categorized as either small cell lung cancer or NSCLC (22). NSCLC accounts for $~ 80 \%$ of patients with lung cancer, and the majority of patients with NSCLC are diagnosed during the mid-late stages of the disease, and thus may no longer be subjected to operative therapy (3). Radiotherapy, chemotherapy and molecular targeted therapy represent current therapeutic strategies for the treatment of patients with NSCLC, however, the use of such strategies has not significantly improved the survival rate of patients with lung cancer (18).
A

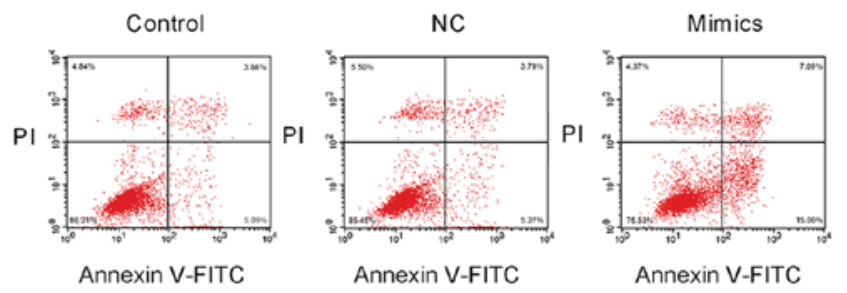

B

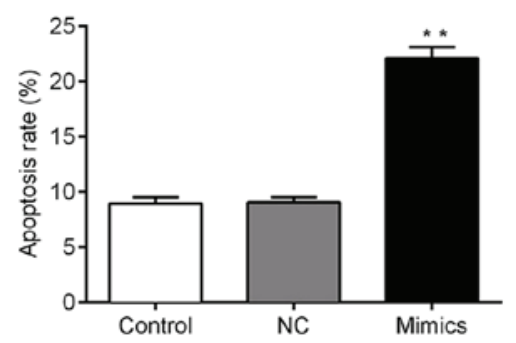

C

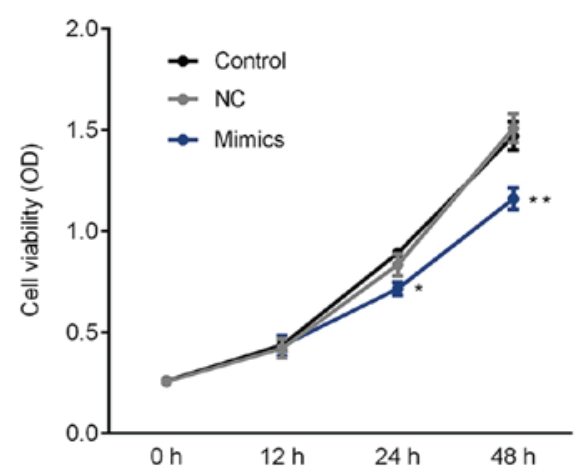

Figure 4. miR-140-5p suppresses the proliferation of NSCLC cells via regulation of YES1 expression. (A) Flow cytometry scatter plots of the control, $\mathrm{NC}$ and mimics groups. (B) Flow cytometry results were analyzed quantitatively to determine the rate of apoptosis in each group. (C) Cells transfected with miR-140-5p mimics exhibited decreased levels of viability. Data are presented as the mean \pm standard deviation of three independent experiments. ${ }^{*} \mathrm{P}<0.05$ and ${ }^{* * *} \mathrm{P}<0.01$ vs. the $\mathrm{NC}$ group. NC, negative control; NSCLC, non-small cell lung cancer; PI, propidium iodide; OD, optical density; FITC, fluorescein isothiocyanate; miR, microRNA.

miRNAs are widely and stably expressed in human body fluids (24). Aberrant levels of circulating miRNAs represent potential biomarkers for the early diagnosis of tumors as well as for the prediction of therapeutic responses (25). miRNAs exhibit important regulatory roles by targeting mRNAs for protein cleavage or translational repression (3). Considering that $>50 \%$ of miRNAs are located in cancer-associated genomic regions or in fragile sites, miRNAs may serve an important role in cancer pathogenesis (26). Furthermore, aberrant miRNA expression has been demonstrated in lung cancer, which contributes to carcinogenesis and cancer development by either promoting oncogene expression or inhibiting tumor suppressor genes (27). miR-140-5p was found to serve a role in carcinogenesis of $\operatorname{NSCLC}(21,22)$. Target genes associated with miR-140-5p may serve as biomarkers and aid in the diagnosis and prognostic prediction of NSCLC $(28,29)$. The miR-140-5p/monocyte to macrophage differentiation-associated (MMD) axis could affect cell proliferation and invasion of lung cancer cells by 
A

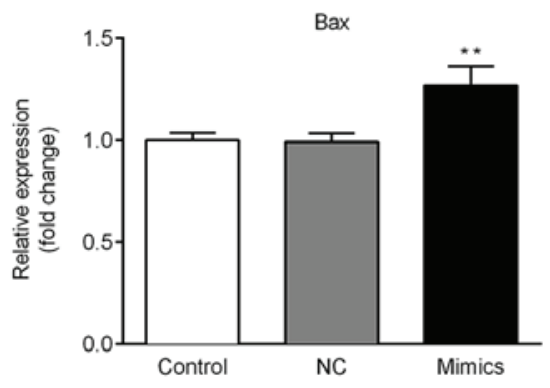

D

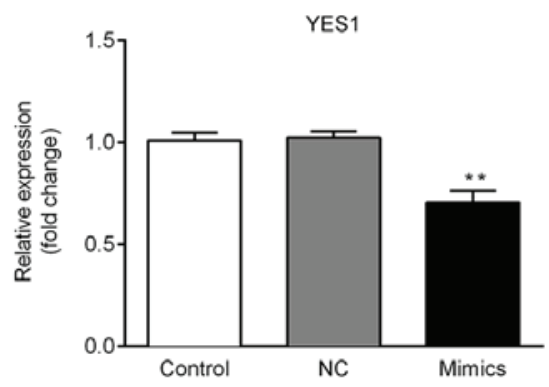

B

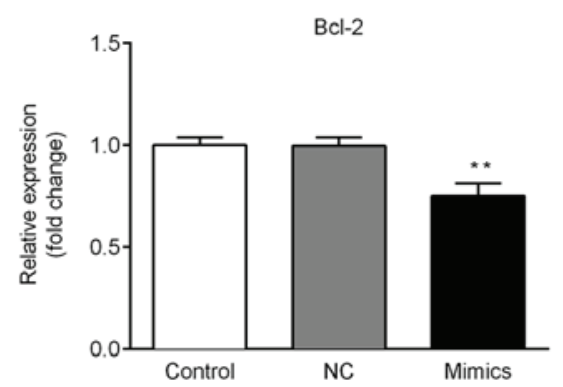

E

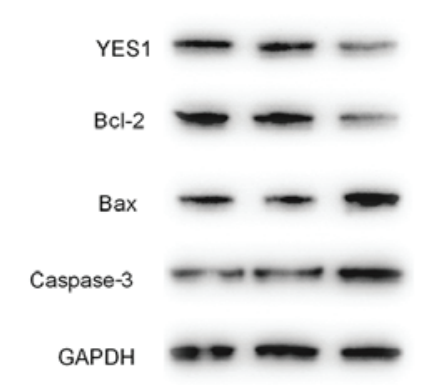

C

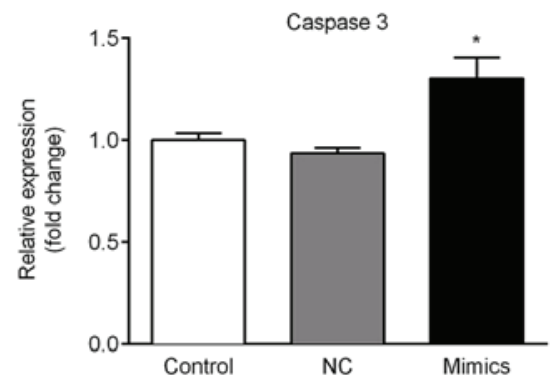

Figure 5. miR-140-5p may regulate cell viability by targeting YES1. Effect of transfection with miR-140-5p mimics in A549 cells on mRNA expression of (A) Bax, (B) Bcl-2, (C) caspase-3 and (D) YES1. (E) A representative western blot image of YES1, Bcl-2, Bax and caspase-3 expression levels. (F) Quantitative analysis western blotting. Data are presented as the mean \pm standard deviation of three independent experiments. ${ }^{*} \mathrm{P}<0.05$ and ${ }^{* *} \mathrm{P}<0.01 \mathrm{vs}$. the $\mathrm{NC}$ group. miR, microRNA; Bcl-2, B-cell lymphoma 2; YES1, YES proto-oncogene 1; Bax, Bcl-2 associated X; miR, microRNA.

regulating the Erk signaling pathway $(21,22)$. In the present study, miR-140-5p expression was demonstrated to be markedly decreased in NSCLC tissues compared with normal adjacent tissues.

YES1 is an important oncogene belonging to the Src protein-tyrosine kinase family (30). Increasing evidence has indicated that YES1 is overexpressed in numerous types of cancer and promotes the proliferation and metastasis of tumor cells, which may have potential therapeutic applications regarding the clinical diagnosis and treatment of tumors (31-34). However, whether miR-140-5p may inhibit proliferation and induce apoptosis of NSCLC cells via targeting of YES1 remains unclear. Differential expression of miR-140-5p has been revealed in numerous signaling pathways associated with the regulation of cell apoptosis $(21,22)$. A previous study demonstrated that the YES1 is a target gene of miR-140-5p (35). In the current study, target genes of miR-140-5p were predicted using TargetScan bioinformatics software, and the results revealed that the YES1 oncogene represented a potential target of miR-140-5p. Furthermore, the results of the present study revealed that ectopic expression of miR-140-5p suppressed NSCLC viability and promoted apoptosis.

Apoptosis serves an important role in anti-carcinogenesis (36). The Bcl-2 protein family and the caspase family are currently the most frequently investigated genes $(37,38)$. Bcl-2 and Bax are the most important regulatory genes in the apoptotic pathway with opposing regulatory functions (37). The anti-apoptotic gene Bcl-2 was the first anti-apoptotic gene discovered in biomedical research (39). Bax is a pro-apoptotic gene opposing the activity of apoptosis-inhibiting proteins, including $\mathrm{Bcl}-2$, to prevent the anti-apoptotic effects (40).
Caspase-3 is a physiological enzymatic protease of Bcl-2 involved in the process of apoptosis (41). In the current study, overexpression of miR-140-5p in A549 cells markedly inhibited YES1 and Bcl-2 expression; however, the protein expression levels of $\mathrm{Bax}$ and caspase- 3 were upregulated following transfection with miR-140-5p, compared with the NC group. The apoptosis rate of A549 cells following transfection with miR-140-5p mimics increased compared with the NC group, and transfection with miR-140-5p mimics suppressed the level of cell viability. These results may be used for the development of a novel diagnostic or therapeutic strategy and may indicate potential therapeutic targets for NSCLC. The current study was limited by the use of only one cell line, and in future studies, multiple cell lines will be used to verify these results.

In conclusion, the present study revealed a novel target gene of miR-140-5p associated with the regulation of lung cancer cell apoptosis and viability.

\section{Acknowledgements}

Not applicable.

\section{Funding}

No funding was received.

\section{Availability of data and materials}

The datasets used and/or analyzed during the current study are available from the corresponding author on reasonable request. 


\section{Authors' contributions}

WZ contributed to the analysis and interpretation of data, conception and design. XW and DY were responsible for the acquisition of data and writing of the manuscript. LX, HW and $\mathrm{ZM}$ contributed to the acquisition, analysis and interpretation of data. ZW and YS performed statistical analysis. QZ provided technical support, and contributed to the analysis and interpretation of data. $\mathrm{ZZ}$ contributed to the conception and design of the study, interpretation of data and revision of the manuscript. YY was responsible for the conception, design and supervision of the study, and the revision of the manuscript.

\section{Ethics approval and consent to participate}

The present study was approved by the Ethics Committee of Qinhuangdao First People's Hospital (Qinhuangdao, China) and written informed consent was obtained from each participant prior to the study.

\section{Patient consent for publication}

All patients provided consent for publication.

\section{Competing interests}

The authors declare that they have no competing interests.

\section{References}

1. Liu P, Pu J, Zhang J, Chen Z, Wei K and Shi L: Bioinformatic analysis of miR-4792 regulates Radix Tetrastigma hemsleyani flavone to inhibit proliferation, invasion, and induce apoptosis of A549 cells. Onco Targets Ther 12: 1401-1412, 2019.

2. Pope CA III, Burnett RT, Thun MJ, Calle EE, Krewski D, Ito K and Thurston GD: Lung cancer, cardiopulmonary mortality, and long-term exposure to fine particulate air pollution. JAMA 287: 1132-1141, 2002

3. Sui A, Zhang X and Zhu Q: Diagnostic value of serum miR197 and miR145 in non-small cell lung cancer. Oncol Lett 17: 3247-3252, 2019

4. Lynch TJ, Bell DW, Sordella R, Gurubhagavatula S, Okimoto RA, Brannigan BW, Harris PL, Haserlat SM, Supko JG, Haluska FG, et al: Activating mutations in the epidermal growth factor receptor underlying responsiveness of non-small-cell lung cancer to gefitinib. N Engl J Med 350 2129-2139, 2004.

5. Carvalho PE, Antonãngelo L, Bernardi FD, Leão LE, Rodrigues OR and Capelozzi VL: Useful prognostic panel markers to express the biological tumor status in resected lung adenocarcinomas. Jpn J Clin Oncol 30: 478-486, 2000.

6. Bartel DP: MicroRNAs: Target recognition and regulatory functions. Cell 136: 215-233, 2009.

7. Ambros V: The functions of animal microRNAs. Nature 431: 350-355, 2004.

8. Valadi H, Ekström K, Bossios A, Sjöstrand M, Lee JJ and Lötvall JO: Exosome-mediated transfer of mRNAs and microRNAs is a novel mechanism of genetic exchange between cells. Nat Cell Biol 9: 654-659, 2007.

9. He L and Hannon GJ: MicroRNAs: Small RNAs with a big role in gene regulation. Nat Rev Genet 5: 522-531, 2004.

10. Taylor DD and Gercel-Taylor C: MicroRNA signatures of tumor-derived exosomes as diagnostic biomarkers of ovarian cancer. Gynecol Oncol 110: 13-21, 2008.

11. Dews M, Homayouni A, Yu D, Murphy D, Sevignani C, Wentzel E, Furth EE, Lee WM, Enders GH, Mendell JT and Thomas-Tikhonenko A: Augmentation of tumor angiogenesis by a Myc-activated microRNA cluster. Nat Genet 38: 1060-1065, 2006.
12. Ladeiro Y, Couchy G, Balabaud C, Bioulac-Sage P, Pelletier L, Rebouissou S and Zucman-Rossi J: MicroRNA profiling in hepatocellular tumors is associated with clinical features and oncogene/tumor suppressor gene mutations. Hepatology 47: 1955-1963, 2008.

13. Mitra R, Edmonds MD, Sun J, Zhao M, Yu H, Eischen CM and Zhao Z: Reproducible combinatorial regulatory networks elucidate novel oncogenic microRNAs in non-small cell lung cancer. RNA 20: 1356-1368, 2014.

14. Wozniak MB, Scelo G, Muller DC, Mukeria A, Zaridze D and Brennan P: Circulating microRNAs as non-invasive biomarkers for early detection of non-small-cell lung cancer. PLoS One 10: e0125026, 2015.

15. Yao Q, Zhang AM, Ma H, Lin S, Wang XX, Sun JG and Chen ZT: Novel molecular beacons to monitor microRNAs in non-small-cell lung cancer. Mol Cell Probes 26: 182-187, 2012.

16. Goga A and Benz C: Anti-oncomir suppression of tumor phenotypes. Mol Interv 7: 199-202, 180, 2007.

17. Yan X, Zhu Z, Xu S, Yang LN, Liao XH, Zheng M, Yang D, Wang J, Chen D, Wang L, et al: MicroRNA-140-5p inhibits hepatocellular carcinoma by directly targeting the unique isomerase Pin1 to block multiple cancer-driving pathways. Sci Rep 7: 45915, 2017.

18. Zhou CW, Zhao WJ, Zhu YG and Zhao XD: MiR-185 inhibits tumor growth and enhances chemo-resistance via targeting SRY-related high mobility group box transcription factor 13 in non-small-cell carcinoma. Am J Transl Res 10: 2600-2609, 2018.

19. Yang H, Fang F, Chang R, and Yang L: MicroRNA-140-5p suppresses tumor growth and metastasis by targeting transforming growth factor $\beta$ receptor 1 and fibroblast growth factor 9 in hepatocellular carcinoma. Hepatology 58: 205-217, 2013.

20. Zhang W, Zou C, Pan L, Xu Y, Qi W, Ma G, Hou Y and Jiang P: MicroRNA-140-5p inhibits the progression of colorectal cancer by targeting VEGFA. Cell Physiol Biochem 37: 1123-1133, 2015.

21. Dong C, Liu X, Wang H, Li J, Dai L, Li J and Xu Z: Hypoxic non-small-cell lung cancer cell-derived exosomal miR-21 promotes resistance of normoxic cell to cisplatin. Onco Targets Ther 12: 1947-1956, 2019.

22. Flamini V, Jiang WG and Cui Y: Therapeutic Role of MiR-140-5p for the treatment of non-small cell lung cancer. Anticancer Res 37: 4319-4327, 2017.

23. Livak KJ and Schmittgen TD: Analysis of relative gene expression data using real-time quantitative PCR and the 2(-Delta Delta C(T)) method. Methods 25: 402-408, 2001.

24. Arcà B, Colantoni A, Fiorillo C, Severini F, Benes V, Di Luca M, Calogero RA and Lombardo F: MicroRNAs from saliva of anopheline mosquitoes mimic human endogenous miRNAs and may contribute to vector-host-pathogen interactions. Sci Rep 9: 2955, 2019.

25. Mirzaei H, Khataminfar S, Mohammadparast S, Sales SS, Maftouh M, Mohammadi M, Simonian M, Parizadeh SM, Hassanian SM and Avan A: Circulating microRNAs as potential diagnostic biomarkers and therapeutic targets in gastric cancer: Current status and future perspectives. Curr Med Chem 23: 4135-4150, 2016.

26. Long XB, Sun GB, Hu S, Liang GT, Wang N, Zhang XH, Cao PP Zhen HT, Cui YH and Liu Z: Let-7a microRNA functions as a potential tumor suppressor in human laryngeal cancer. Oncol Rep 22: 1189-1195, 2009.

27. Cheng TF, Choudhuri S, and Muldoon-Jacobs K: Epigenetic targets of some toxicologically relevant metals: A review of the literature. J Appl Toxicol 32: 643-653, 2012.

28. Wang K, Chen M and Wu W: Analysis of microRNA (miRNA) expression profiles reveals 11 key biomarkers associated with non-small cell lung cancer. World J Surg Oncol 15: 175, 2017.

29. Hu L, Ai J, Long H, Liu W, Wang X, Zuo Y, Li Y, Wu Q and Deng Y: Integrative microRNA and gene profiling data analysis reveals novel biomarkers and mechanisms for lung cancer. Oncotarget 7: 8441-8454, 2016.

30. Xiao X, Mruk DD, Lee WM and Cheng CY: c-Yes regulates cell adhesion at the blood-testis barrier and the apical ectoplasmic specialization in the seminiferous epithelium of rat testes. Int $\mathrm{J}$ Biochem Cell Biol 43: 651-665, 2011.

31. Bilal E, Alexe G, Yao M, Cong L, Kulkarni A, Ginjala V, Toppmeyer D, Ganesan S and Bhanot G: Identification of the YES1 kinase as a therapeutic target in basal-like breast cancers. Genes Cancer 1: 1063-1073, 2010.

32. Seki T, Fujii G, Mori S, Tamaoki N and Shibuya M: Amplification of c-yes-1 proto-oncogene in a primary human gastric cancer. Jpn J Cancer Res 76: 907-910, 1985. 
33. Liu L, Yang J, Zhu X, Li D, Lv Z and Zhang X: Long noncoding RNA H19 competitively binds miR-17-5p to regulate YES1 expression in thyroid cancer. FEBS J 283: 2326-2339, 2016.

34. Lee SA, Kim JS, Park SY, Kim HJ, Yu SK, Kim CS, Chun HS, Kim J, Park JT, Go D and Kim DK: miR-203 downregulates Yes-1 and suppresses oncogenic activity in human oral cancer cells. J Biosci Bioeng 120: 351-358, 2015.

35. Fang Z, Yin S, Sun R, Zhang S, Fu M, Wu Y, Zhang T, Khaliq J and Li Y: miR-140-5p suppresses the proliferation, migration and invasion of gastric cancer by regulating YES1. Mol Cancer 16: 139, 2017.

36. Mohamed MS, Bishr MK, Almutairi FM and Ali AG: Inhibitors of apoptosis: Clinical implications in cancer. Apoptosis 22: 1487-1509, 2017.

37. Warren CFA, Wong-Brown MW and Bowden NA: BCL-2 family isoforms in apoptosis and cancer. Cell Death Dis 10: 177, 2019.
38. Julien $\mathrm{O}$ and Wells JA: Caspases and their substrates. Cell Death Differ 24: 1380-1389, 2017.

39. Adams CM, Clark-Garvey S, Porcu $P$ and Eischen CM: Targeting the Bcl-2 family in B cell lymphoma. Front Oncol 8: 636, 2019.

40. Lin L, Cheng K, Xie Z, Chen C, Chen L, Huang Y and Liang Z: Purification and characterization a polysaccharide from Hedyotis diffusa and its apoptosis inducing activity toward human lung cancer cell line A549. Int J Biol Macromol 122: 64-71, 2019.

41. Xu P, Cai X, Zhang W, Li Y, Qiu P, Lu D and He X: Flavonoids of Rosa roxburghii Tratt exhibit radioprotection and anti-apoptosis properties via the $\mathrm{Bcl}-2(\mathrm{Ca}(2+)) /$ Caspase-3/PARP-1 pathway. Apoptosis 21: 1125-1143, 2016. 